\title{
Simple Virilizing 21-Hydroxylase Deficiency
}

National Cancer Institute

\section{Source}

National Cancer Institute. Simple Virilizing 21-Hydroxylase Deficiency. NCI Thesaurus.

Code C132096.

A classic form of congenital adrenal hyperplasia that is characterized by severe 21-

hydroxylase deficiency, resulting in glucocorticoid and mineralocorticoid deficiency, but without clinically significant salt wasting, and with androg en excess, which causes virilization in female infants. 